\title{
Periphlebitis retinae and multiple sclerosis
}

\author{
E. J. FIELD AND J. B. FOSTER \\ From the Medical Research Council Research Group on Demyelinating Disease and the \\ Department of Neurology, Royal Victoria Infirmary, Newcastle-upon-Tyne
}

It is generally accepted that many of the early lesions of disseminated sclerosis are centred around small veins in the central nervous system. Reports, therefore, that periphlebitis retinae is a not infrequent accompaniment of the disease (Rucker, 1945; Haarr, 1953; Orban, 1955; Loewe, 1958; Ardouin, Feuvrier, and Catros, 1960; Scott, 1961) seem to offer an opportunity of observing changes which might well be a mirror of what may be presumed to happen in the depths of the nervous tissues.

The availability of a large number of well-documented cases of disseminated sclerosis of varying acuteness and severity has enabled us to re-investigate the alleged occurrence of retinal periphlebitis, of which the frequency recorded by different workers varies considerably (see below).

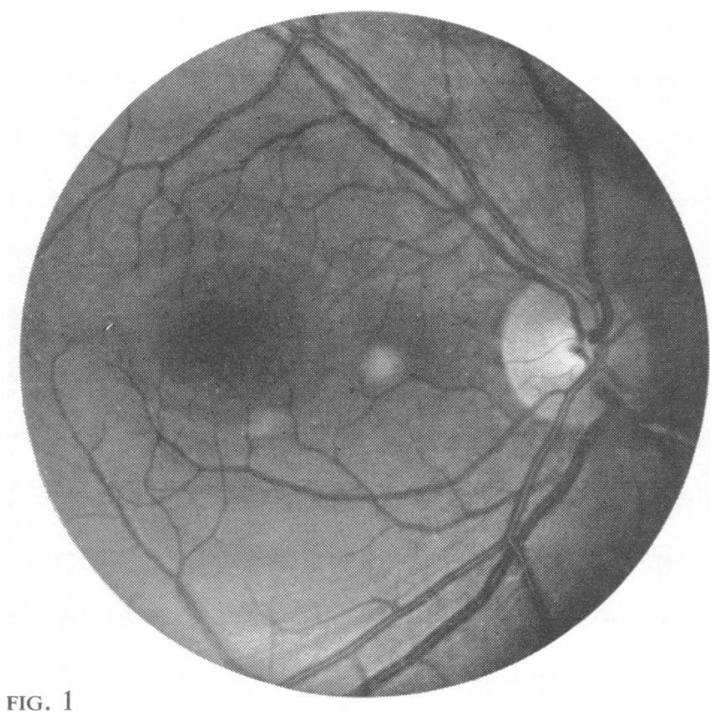

\section{MATERIAL AND METHODS}

One hundred and thirty cases of disseminated sclerosis have been carefully examined in this department over the last two years during the course of various therapeutic trials. In addition 20 ophthalmologically normal subjects (mainly from the dermatological department and the medical wards, together with one or two medical students) were examined (and sometimes photographed) with a Zeiss retinal camera. All fundi were searched with the possibility of periphlebitis in mind, the majority under full mydriasis. In no case was any sign of periphlebitis retinae seen either at the periphery of the retina or near the disc. The well-known colloid spots at the macula and small dark choroidal ring-like degenerated areas were

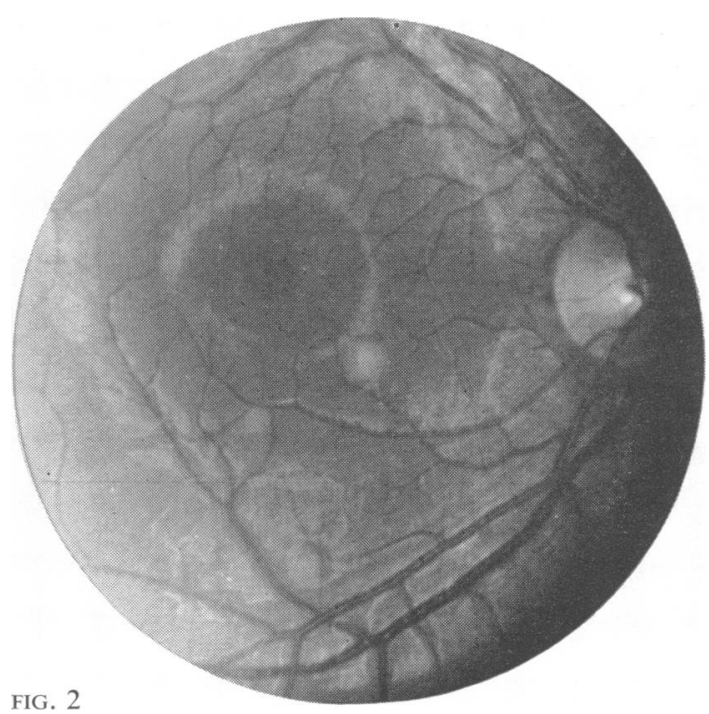

FIG. 2

FIG. 2. The same fundus with light moved slightly to one side. Note the cotton wool-like appearance simulating exudation accompanying many of the vessels, and in part covering them over, particularly below and lateral to the disc. This appearance is artefactual. 
occasionally observed; in addition, of course, disc changes were commonly present. Forty of the earlier cases in our series were photographed and a considerable number of the later ones examined with the same machine though they presented nothing worthy of record. We did, however, encounter an artefactual appearance which, we feel, may have been mistaken for a true periphlebitis and may have given rise to some of the high incidence rates recorded. A retina which shows no abnormality (Fig. 1) may when the angle of incident light is slightly altered show a reflex which can be confusing (Fig. 2). Not all retinas show this phenomenon and its degree is variable. In our experience something like $10-20 \%$ of cases of disseminated sclerosis showed this reflex. No doubt it does correspond with some structural feature such as prominent relief of vessels against the retinal background but this is not pathological and occurs in normal eyes. The greyish-white cotton wool or veillike appearance simulating a filmy exudate shown in Fig. 2 corresponds well with the description and illustration given by Loewe (1958) in some of her cases ('. . . Veneneinscheidungen zeigten vorwiegend ein grauweisses, wallfadenartiges Aussehen ... als breite unscharf konturierte Streifen . . . , von denen die Gefässe teilweise verdeckt wurden'). In the lower part of Fig. 2, a white 'seam' apparently accompanies the vessels. Similar appearances were described by Orban (1955) who also speaks of a greyish-white infiltration on one or both sides of a vein and showing a fluffy margin. Sometimes a vein appeared to him partially or completely covered by this exudate.

Inability to confirm the finding of periphlebitis in our disseminated sclerosis survey material inclines us to doubt whether some of the reports do in fact deal with this disease or whether they are in reality based upon cases of primary retinal vasculitis accompanied by nervous signs as described recently by White (1961). White's paper reviews the literature of the association and we need only refer to certain articles dealing specifically with periphlebitis in association with disseminated sclerosis to indicate the wide differences in reported frequency (Rucker, $1945,16 \%$; Haarr, 1953, 22.8\%: Orban, 1955, 42.0\%: Loewe, 1958, 20.3\%; Ardouin, Feuvrier, and Catros, 1960, $33.0 \%$; Scott, $1961,17 \%)$.

\section{SUMMARY}

One hundred and thirty cases of disseminated sclerosis in all stages of the disease were examined specifically for the occurrence of periphlebitis retinae. No instance of the condition was noted and it is suggested that the association of primary retinal vasculitis with neurological signs is perhaps the basis for the alleged occurrence of periphlebitis retinae in disseminated sclerosis.

\section{REFERENCES}

Ardouin, M., Feuvrier, Y., and Catros, A. (1960), Rev. Oto-neuroophthal., $32,3$.

Haarr, M. (1953). Acta psychiat. scand., 28, 175.

Loewe, I. (1958). Z. ärztl. Forsch., 23, 976.

Orban, I. (1955). Orv. Hetil., 96, 406.

Rucker, C. W. (1945). J. Amer. med. Ass., 127, 970.

Scott, G. I. (1961). Proc. roy. Soc. Med., 54, 38.

White, R. H. R. (1961). Brain, 84, 262. 